\title{
Dietary Spirulina (Arthrospira platensis) Supplementation on Growth Performance, Haematology, Immune Response and Disease Resistance of Rugose Frog (Hoplobatrachus rugulosus)
}

\author{
Tarika Thip-uten $^{1}$ (D) Patcharaporn Tippayawat $^{2}(\mathbb{D})$ Bundit Yuangsoi $^{1}$ (D) \\ and Sutee Wongmaneeprateep ${ }^{1 *}$
}

${ }^{1}$ Department of Fisheries, Faculty of Agriculture, Khon Kaen University, Khon Kaen Province - 40002, Thailand. ${ }^{2}$ Department of Medical Technology, Centre for Research and Development of Medical Diagnostic Laboratories, Faculty of Associated Medical Sciences, Khon Kaen University, Khon Kaen Province - 40002, Thailand.

\begin{abstract}
The present study aimed to investigate the effects of dietary Spirulina (Arthrospira platensis) supplementation on the growth, survival, haematology, immune parameters and disease resistance of Rugose frog (Hoplobatrachus rugulosus) against Aeromonas hydrophila infection. Frogs were fed a formulated diet containing Spirulina as $0 \%$ (control), 1.5\%, 3.0\%, 4.5\%, and $6.0 \%$ for a period of eight weeks. The results indicated that growth parameters; final body weight, weight gain, average daily gain, specific growth rate, feed conversion ratio, and survival rate of frog fed with $A$. platensis at the level of $4.5 \%$ showed best values but not significantly different $(P>0.05)$. However, haematological values; leukocytes, erythrocytes, haemoglobin, and haematocrit levels were highest and significantly different $(P<0.05)$ when compared to the control group. Disease resistance was tested by challenging with $A$. hydrophila after eight weeks of feeding. The results showed that frog fed with $4.5 \% A$. platensis showed significantly $(P<0.05)$ higher survival rate and highest resistance to $A$. hydrophila in comparison with the other groups. Leukocyte, erythrocyte, complement $\mathrm{C} 3$, and immunoglobulin $\mathrm{G}$ levels of frogs fed with $4.5 \%$ A. platensis were found to be significantly $(P<0.05)$ differed compared with control. In conclusion, diet supplemented with Spirulina at the level of $4.5 \%$ could improve growth performance, haematological and immune parameters, and $A$. hydrophila resistance in Rugose frogs.

Keywords: Arthrospira platensis, Aeromonas hydrophila, Hoplobatrachus rugulosus haematology value, immune response
\end{abstract}

\footnotetext{
*Correspondence: sutee_8888@hotmail.com

(Received: March 01, 2021; accepted: June 01, 2021)

Citation: Thip-uten T, Tippayawat P, Yuangsoi B, Wongmaneeprateep S. Dietary Spirulina (Arthrospira platensis) Supplementation on Growth Performance, Haematology, Immune Response and Disease Resistance of Rugose Frog (Hoplobatrachus rugulosus). J Pure Appl Microbiol. 2021;15(3):1139-1149. doi: 10.22207/JPAM.15.3.03

(C) The Author(s) 2021. Open Access. This article is distributed under the terms of the Creative Commons Attribution 4.0 International License which permits unrestricted use, sharing, distribution, and reproduction in any medium, provided you give appropriate credit to the original author(s) and the source, provide a link to the Creative Commons license, and indicate if changes were made.
} 


\section{INTRODUCTION}

Rugose frog (Hoplobatrachus rugulosus), an economic species, is widely cultivated due to their rapid growth, less cultivation area, and short cultivating time. As a culinary delicacy this product is in high demand, not only locally but also internationally. To meet the demands of the market place there is intensive cultivation of this species of frog in Thailand, with cultivation intensity ranging from 50 to 150 frogs per square meters depending on a variety of cultivation methods. The managements of individual cultivation sites varies and includes earthen ponds, cement tanks, and cage cultivations. Generally these farmed frogs are fed on a high protein pelleted diet, which often gives rise to management and production problems. In practice, intensive cultivation, if combined with inadequate feeding regimes, can result in cannibalism and lack of uniform growth. Farmers attempt to counter this through regularly monitoring growth rates. The other issues are water quality, pollution, and bacterial infections, especially $A$. hydrophila, leading to Red Leg disease. This disease, if unchecked, can result in high mortality rate of $60 \%$ to $80 \%^{1-5}$.

Accordingly, farmers may apply antibiotics to cure various disease, yet this often generates unwanted side effects such as the bio-accumulation of chemical additives in the frogs, Over time many diseases become antibiotic resistant. To manage these issues effectively immune stimulants, may be mixed with the feeding diet of frogs to encourage growth, survival rate, immune stimulation, and disease resistance. Many researchers have employed Spirulina (Arthrospira platensis) as immune stimulants in various aquatic animals, namely, African catfish (Clarias gariepinus), common carp (Cyprinus carpio), gibel carp (Carassius auratus gibelio), great sturgeon (Huso huso), Nile tilapia (Oreochromis niloticus), rainbow trout (Oncorhynchus mykiss) Pacific white shrimp (Litopenaeus vannamei) $)^{6-15}$. Arthrospira platensis, a blue-green alga, contains the proportion (\% dried weight) of protein, carbohydrate, and fat, ranging from 55 to $70 \%, 15$ to $20 \%$, and $7 \%$, respectively.

Moreover, it acquires vital vitamins and minerals like gamma-linolenic acid (GLA), chlorophyll, carotenoids, phycocyanin, and superoxide dismutase (SOD). Therefore, the properties of A.platensis considerably are antioxidant, immunomodulatory, and antiinflammatory ${ }^{16-21}$.

This research investigates the effects of combining the different levels of $A$. platensis into feeding formula given to frogs, on their growth, haematology, immune response, and disease resistance, especially with respect to the infection of $A$. hydrophila in Hoplobatrachus rugulosus cultivated in cement tanks. A primary focus of this research was to ascertain the optimal level of A. platensis as a dietary supplement to stimulate growth and minimize disease, to promote the economic efficiencies of frog production and thereby enhance farmers' income.

\section{MATERIALS AND METHODS}

The effect of $A$. platensis on growth, survival, haematology and immune response in H. rugulosus

\section{Experimental design}

The experimental design is Completely Randomized Design (CRD) and divided into five treatments with triplication. In each treatment, 150 frogs were fed with diet containing combining $40 \%$ protein with different levels of Arthrospira platensis for 8 weeks.

Treatment 1 (T1 as control): frogs were fed with diet without combining $A$. platensis ( $0 \%)$. Treatment 2 (T2): frogs were fed with diet in the ratio of 15 grams of $A$. platensis per one kilogram of diet (1.5\%).

Treatment 3 (T3): frogs were fed with diet in the ratio of 30 grams of $A$. platensis per one kilogram of diet (3.0\%).

Treatment 4 (T4): frogs were fed with diet in the ratio of 45 grams of $A$. platensis per one kilogram of diet (4.5\%).

Treatment 5 (T5): frogs were fed with diet in the ratio of 60 grams of $A$. platensis per one kilogram of diet (6.0\%).

\section{Frog preparation}

Seven hundred and fifty juvenile one month old Rugose frogs were sourced from a commercial farm, located in Harng Hong Subdistrict, Mueang District, Sakon Nakhon Province and then nursed at the hatchery farm managed by the Department of Fisheries, Faculty of Agricultural Technology, Sakon Nakhon Rajabhat University. The frogs were cultured in three fiberglass tanks with diameters $(1.2 \mathrm{~m})$ and 
heights of $(1.5 \mathrm{~m})$. Each tank was covered by mesh shading to prevent an any enemies from getting inside. The control diet formula was fed twice daily at 08.30 and 16.30 . Before conducting the experiment, frogs of a similar size were randomly selected and acclimated for seven days in 15 cement tanks, each tank with a diameter of 1 meter and height of 50 centimeters 50 frogs per tank. The cement tank was filled with tap water to the level of seven centimeters, and stored for seven days to ensure dechlorination. After that, water quality parameter were adjusted to suit the frogs' cultivation, including dissolved oxygen at $4 \mathrm{mg} / \mathrm{L}$, water temperature of 26 to $30^{\circ} \mathrm{C}, \mathrm{pH}$ of 7.50 to 8.50 , total alkalinity of 80 to $150 \mathrm{mg} / \mathrm{L}$ as $\mathrm{CaCO}_{3}$, and total ammonia nitrogen (TAN) of less than $0.10 \mathrm{mg} / \mathrm{L}$. After preparation, the specimens were measured for their initial body weights (10.47 to $10.64 \mathrm{~g}$ ) and fed with the different diet formulas. The water in the tank was changed every two days, and its qualities were analyzed at the laboratory to control and maintain suitable water properties for the cultivation ${ }^{22}$. $\mathrm{pH}$ levels, dissolved oxygen levels, and water temperature were determined by using multi-parameter meter (CyberScan PCD650, Eutech Instruments). Total alkalinity and TAN were measured in accordance with APHA et $a^{23}$.

\section{Diet preparation}

Instant powder of Arthrospira platensis sourced from the Marine Leader Co., Ltd. containing $62 \%$ protein by dried weight was combined in different levels for individual treatments. The required level of nutrition required for the frogs was calculated following the techniques outlined by Somsueb \& Boonyaratpalin ${ }^{24}$ as shown in Table 1 . The feeding diet was pelletized by floating pellet extruder. All the pelletized material was dried in a hot air oven at $60^{\circ} \mathrm{C}$ to ensure the moisture level at lower 10 and then placed in sanitized containers. Importantly, the individual feeding diet was analyzed for its chemical compositions; specifically, dry matter (DM), ash, crude protein $(\mathrm{CP})$, ether extract (EE), and crude fibre (CF) using AOAC method ${ }^{25}$. Nitrogen free extract (NFE) and digestible energy (DE) were calculated by applying the NRC method $^{26}$. Chemical composition of each trial feeding diet is displayed in Table 1.

An amount of feeding diet was $5 \%$ based on frogs' weight and provided twice a day at 08.30 and 16.30. The feeding diet was placed on the diet tray, situated on the floating substrate for the frogs. Thereafter, the frogs' feeding behaviour were investigated.

\section{Growth performance, haematological and} immune parameters

Growth, survival, haematology, and immune response of Rugose frogs were measured after eight weeks of cultivation. Several parameters indicating frog growths, namely final body weight (FBW; g), weight gain (WG; g), average daily gain (ADG; g/day), specific growth rate, (SGR; \%/day), and feed conversion ratio (FCR) were measured. The remaining frogs were recorded to calculate survival rate (SR; \%)

Fifteen frogs from each treatment were randomly selected to collect blood samples. Before blood collection, each frog was anesthetized with isoflurane following the method of Smith and Stump ${ }^{27}$. Blood samples were drawn via a cardiac puncture of each frog following the method outlined by Heatley et $\mathrm{al}^{28}$. The collected blood was immediately transferred to the test tubes coated with two coated anticoagulants. Ethylenediamine tetra-acetic acid (EDTA) anticoagulant for haematology analysis, and heparin for immune response analysis.

\section{Bacterial culture and challenge experiments Pathogen preparation}

A stock of Aeromonas hydrophila was obtained from the Faculty of Associated Medical Sciences, Khon Kaen University. A single colony was isolated into the test tubes containing $5 \mathrm{~mL}$ of nutrient broth (NB) and then incubated at $37^{\circ} \mathrm{C}$ for 8 to $24 \mathrm{~h}$ to duplicate the bacterium. After that, the culture in log phase was centrifuged at 10,000 rpm at $4^{\circ} \mathrm{C}$ for $10 \mathrm{~min}$. Then, the pellet was collected and mixed with normal saline (NSS) to a volume of $5 \mathrm{~mL}$. The mixure was then centrifuged again at $10,000 \mathrm{rpm}$ at $4^{\circ} \mathrm{C}$ for $10 \mathrm{~min}$ and the pellet was saved and mixed with normal saline (NSS) 1,000 $\mu \mathrm{L}$. The disease's turbidity was then measured by optical density (OD) at $600 \mathrm{~nm}$.

\section{Challenge test}

In the preliminary challenge test, ten frogs (approximately 50-60 g) were used for each treatment to calculate the lethal dose $50\left(\mathrm{LD}_{50}\right)$. Each frog was injected intramuscularly with 0.2 $\mathrm{mL}$ of sterilized normal saline solution (NSS, $\mathrm{NaCl}$ $0.85 \% \mathrm{w} / \mathrm{v}$ ) containing $A$. hydrophila ranging from $10^{6}$ to $10^{9} \mathrm{CFU} / \mathrm{mL}$. A mock injection was given 
to the control group with NSS. Mortalities were recorded daily for 7 days and then calculated. The seven-day $\mathrm{LD}_{50}$ of $A$. hydrophila for the challenge test was $5.2 \times 10^{8} \mathrm{CFU} / \mathrm{mL}$.

After eight weeks of feeding with $A$. platensis supplemented diet (at five different levels), the T1-T5 using sixty frogs per treatment in triplicate groups were selected randomly and injected intramuscularly with $0.2 \mathrm{~mL}$ A. hydrophila suspension $\left(5.2 \times 10^{8} \mathrm{CFU} / \mathrm{mL}\right)$. Challenged frogs were maintained in aquaria (10 frogs/aquarium) and divided into two groups. The first group for frogs' survival rate study after being injected with A. hydrophila for two weeks, and the second group was for the investigation of haematology and the immune response of frogs after being injected with $A$. hydrophila for two days. The first group was observed constantly for clinical signs of disease including behavioural abnormalities and mortality. The cause of mortality was confirmed by re-isolating the organism from moribund or dead frogs. Survival rates of the challenged frogs were calculated at the end of two weeks post injection. For the second group, nine frogs from each treatment on 2 nd day post challenge were segregated for collection of blood to analyze haematological and immunological aspects.

\section{Haematological parameters}

At 8th week of the growth trials and the 2nd day after the challenge test, frogs were

Table 1. Raw material and chemical composition of the ingredients for five treatments with different feed diets

\begin{tabular}{|c|c|c|c|c|c|}
\hline \multirow[t]{2}{*}{ Ingredients (kg) } & \multicolumn{5}{|c|}{ Arthrospira platensis levels in diet (\%) } \\
\hline & $\mathrm{T} 1(0.0 \%)$ & $\mathrm{T} 2(1.5 \%)$ & T3 (3.0\%) & $\mathrm{T} 4$ (4.5\%) & T5 (6.0\%) \\
\hline Fish meal (55 \%CP) & 45 & 40 & 39.5 & 38 & 34 \\
\hline Soybean meal (45 \%CP) & 26 & 29 & 28 & 27 & 30 \\
\hline Rice bran & 12 & 15 & 15 & 16 & 16 \\
\hline Broken rice & 14 & 11.5 & 11.5 & 11.5 & 11 \\
\hline Arthrospira platensis meal (62 \%CP) & 0.00 & 1.50 & 3.00 & 4.50 & 6.00 \\
\hline Fish oil & 1 & 1 & 1 & 1 & 1 \\
\hline alpha starch & 1 & 1 & 1 & 1 & 1 \\
\hline $\begin{array}{l}\text { */Premix vitamin-mineral for aquatic } \\
\text { animals }\left(\mathrm{SUN}-\mathrm{MIX}^{\circledR}\right)\end{array}$ & 1 & 1 & 1 & 1 & 1 \\
\hline Total & 100 & 100 & 100 & 100 & 100 \\
\hline \multicolumn{6}{|l|}{ Nutrient composition by analysis } \\
\hline \multirow[t]{2}{*}{ Dry matter (DM) } & 88.83 & 88.84 & 88.89 & 88.92 & 88.90 \\
\hline & & & -- $\%$ of $D$ & 1 ---------- & ----- \\
\hline Organic matter (OM) & 87.45 & 88.08 & 88.13 & 88.13 & 88.94 \\
\hline Crude protein (CP) & 40.00 & 39.93 & 40.15 & 39.96 & 40.15 \\
\hline Ether extract (EE) & 17.01 & 17.21 & 17.26 & 17.40 & 17.17 \\
\hline Crude fiber (CF) & 2.34 & 2.74 & 2.79 & 2.91 & 3.12 \\
\hline \#/Nitrogen free extract (NFE) & 28.92 & 29.52 & 29.47 & 29.84 & 30.58 \\
\hline \multicolumn{6}{|c|}{ Energy content, protein: energy ratio and feed cost calculated } \\
\hline $\begin{array}{l}\text { \#/Apparent Digestible Energy } \\
(\mathrm{DE}, \mathrm{kcal} / \mathrm{kg})\end{array}$ & 3208 & 3115 & 3094 & 3049 & 3036 \\
\hline DE: Protein ratio (kcal/ g Protein) & 8.02 & 7.80 & 7.71 & 7.63 & 7.56 \\
\hline Protein: DE (mg Protein/kcal DE) & 124.67 & 128.18 & 129.74 & 131.01 & 132.21 \\
\hline$¥$ Price (Baht/kg) & 29.94 & 33.52 & 38.38 & 42.90 & 46.84 \\
\hline
\end{tabular}

*/Premix vitamin-mineral for aquatic animals (SUN-MIX ${ }^{\circledast}$ ): of $1 \mathrm{~kg}$ has Vitamin-A 500,000 IU, Vitamin-D3 100,000 IU, Vitamin-E 5,000 mg, Vitamin-K 2,000 mg, Vitamin-B1 2,500 mg. Vitamin-B2 1,000 mg, Vitamin-B6 1,000 mg, Vitamin-C 10,000 mg, Vitamin-B12 $10 \mathrm{mg}$, niacin 3,000 mg, pantothenic acid 3,000 mg, folic acid $300 \mathrm{mg}$, inositol 1,000 mg, biotin $10 \mathrm{mg}$ and full filling media substrate $1,000 \mathrm{~g}$.

\#/Nitrogen free extract (NFE) (\%) $=100$ - \% (Crude protein - Crude lipid - Crude fiber - total ash - moisture) ${ }^{16}$

$\# /$ Digestible energy (DE) $(\mathrm{kcal} / 100 \mathrm{~g})=(\%$ Protein $\times 3.5)+(\%$ Lipid $\times 8.0)+(\% \mathrm{NFE} \times 2.5)^{16}$

¥Prize of feedstuffs at May, 2018 from Phu Phan Dairy Cooperative Limited, Sakon Nakhon Province, Thailand. 
randomly selected for blood sample collection. Briefly, $200 \mu \mathrm{L}$ of collected blood samples were stored at $4^{\circ} \mathrm{C}$ before analyzes of leukocyte, erythrocyte, haemoglobin, and haematocrit levels by using Sysmex automatic blood count machine model XS-800i (Automate blood analyzer: XS-800i) (WI-CL-H-001).

\section{Immune parameters}

The non-specific immune response was monitored from phagocytic activity, respiratory burst activity was determined from reactive oxygen species (ROS), and complement activity was measured from complement C3. The specific immune response was determined from immunoglobulin $\mathrm{G}$ (IgG).

\section{Phagocytic and respiratory burst activities}

Leukocytes were prepared at $6 \times 10^{6}$ cell/ $\mathrm{mL}$ by using a microscope at 400 magnification to count and calculate the concentration and the number of leukocyte cells $=$ the counted leukocytes $x 2.5 x$ the dilute ratio. After that, $500 \mu \mathrm{L}$ of FITC (fluorescein isothiocyanate conjugate) at $1 \mathrm{mg} / \mathrm{mL}$ was add to $5 \times 10^{7} \mathrm{CFU} / \mathrm{mL}$ of bacteria, which was then incubated in the dark at $4{ }^{\circ} \mathrm{C}$ for $1 \mathrm{~h}$. Later, the mixture was washed with PBS twice by centrifuging $10,000 \mathrm{rpm}$ for $10 \mathrm{~min}$. The supernatant was then discarded and the bacterial pellet was diluted by adding $1,000 \mu \mathrm{L}$ of Roswell Park Memorial Institute 1640 medium (RPMI 1640 medium). After that, $50 \mu \mathrm{L}$ of leukocyte sample ( $3 \times 10^{5}$ cell) was added into test tubes with $50 \mu \mathrm{L}$ of bacteria labelled FITC and then incubated at $37^{\circ} \mathrm{C}$ for $30 \mathrm{~min}$. After that, $50 \mu \mathrm{L}$ of hydroethidine ( $\mathrm{HE}: 3 \mu \mathrm{g} / \mathrm{ml}$ concentration) was added and the mixure incubated at $37^{\circ} \mathrm{C}$ for $5 \mathrm{~min}$. Finally, the leukocyte sample was washed with PBS twice by centrifigation and then $100 \mu \mathrm{L}$ of 2 of paraformaldehyde in PBS (final concentration $1 \%$ paraformaldehyde) was later added and used for the phagocytic activity and respiratory burst following the existing flow cytometry method ${ }^{29}$. Complement C3 and Immunoglobulin G (IgG) assay

The collected blood samples were centrifuged at 9,000 rpm for $10 \mathrm{~min}$. Later, $200 \mu \mathrm{L}$ of serum from each individual treatment was transferred into eppendorf tube and stored at $-20{ }^{\circ} \mathrm{C}$ before analyzing complement $\mathrm{C} 3$ and immunoglobulin $\mathrm{G}$ (IgG) following the nephelometry method ${ }^{30}$.

\section{Statistical analysis}

The mean values of all the parameters were analyzed by one-way analysis of variance (ANOVA) followed by the Duncan's Multiple Range Test. The mean values were considered significantly different when $P<0.05$. All statistical analysis were performed by SAS Computer Program. Data are presented as means \pm standard deviation.

\section{RESULTS}

The effect of $A$. platensis on growth, survival, haematology and immune response in $H$. rugulosus

Rugose frogs were fed with five different dietary formulae for eight weeks. Each formula contained $40 \%$ protein and a percentage of $A$. platensis, [0 (as control), 1.5\%, 3.0\%, 4.5\%, and $6.0 \%]$. The results showed that final body weight, weight gain, average daily gain, specific growth rate, feed conversion ratio, and survival rate of Rugose frog were not significantly different $(P>0.05)$. However, applying the $4.5 \%$ feeding diet formula, the growth and survival of frogs were higher than other formulas with a final weight of $67.45 \pm 2.20 \mathrm{~g}$, weight gain of $56.88 \pm 0.13 \mathrm{~g}$, average daily gain $1.30 \pm 0.14 \mathrm{~g} /$ day, the specific growth rate of $5.25 \pm 1.23 \% /$ day, feed conversion ratio of $0.95 \pm 0.03$, and survival rate of $70.18 \pm 1.71 \%$ (Table 2).

In terms of the haematological parameters, an amount of leukocyte, erythrocyte, haemoglobin, and haematocrit of Rugose frog showed that frogs fed with $4.5 \%$ Spirulina supplemented diet for eight weeks exhibited higher levels of these parameters, and there were significant differences $(P<0.05)$ when comparing with control group shown in Table 3.

However, in respect of immune responses, both non- specific (phagocytic activity, ROS, and complement ( 3 ) and specific immune response ( $\lg G)$ of Rugose frogs fed with A. platensis for eight weeks were higher (with the highest level at $4.5 \%)$ than control group, there was no significant difference $(P>0.05)$ (Table 4).

\section{Effects of Aeromonas hydrophila infections}

The survival rates of Rugose frogs challenged with Aeromonas hydrophila are shown in Fig. 1. The frogs fed with Arthrospira platensis 
supplemented diets had higher survival rates than control group. The mortality of the challenged frogs was first observed in control group (T1) and cumulative mortalities reached $100 \%$ by the 5 th day after the challenge. On the 7th day after the challenge, the highest survival of $53.33 \%$ was in the group of frogs fed with the $4.5 \% \mathrm{~A}$. platensis supplemented diet (T4), followed by $26.67 \%$ (T3), $20.00 \%$ (T2), and $20.00 \%$ (T5), respectively. Frogs fed with the $4.5 \%$ A. platensis supplemented diet showed significantly $(P<0.05)$ higher survival rates than the other groups. Dead or moribund frogs exhibited symptoms of red leg disease with petechiae on their legs. In other words, it indicated that Rugose frogs fed with $A$. platensis supplemented diet could resist the infection of $A$. hydrophila more than the control group.

The effect of $A$. platensis on the haematological and immune responses in Rugose frogs (after the challenge test ) injection with $A$. hydrophila

The haematological parameters of Rugose frogs fed with Spirulina supplemented diets for eight weeks and later challenged with A.hydrophila over two days (Table 3) showed that frogs cultivated with the $4.5 \%$ A. platensis dietary had the highest levels of leukocyte and erythrocyte. These findings were significantly different $(P<0.05)$ when compared with control group. The immune response (Table 4) showed that phagocytic activity, and ROS of frogs, fed with

Table 2. The initial and final body weight, weight gain, average daily gain, specific growth rate, feed conversion ratio, and survival rate of Rugose frog (Hoplobatrachus rugulosus), fed with five different feeding diet formulas.

\begin{tabular}{lccccc}
\hline \multirow{2}{*}{ Parameters } & \multicolumn{5}{c}{ Arthrospira platensis levels in diet (\%) } \\
\cline { 2 - 6 } & $\mathrm{T} 1(0.0 \%)$ & $\mathrm{T} 2(1.5 \%)$ & $\mathrm{T} 3(3.0 \%)$ & $\mathrm{T} 4(4.5 \%)$ & $\mathrm{T} 5(6.0 \%)$ \\
\hline IBW & $10.53 \pm 0.02$ & $10.64 \pm 0.05$ & $10.56 \pm 0.03$ & $10.57 \pm 0.04$ & $10.47 \pm 0.02$ \\
FBW & $64.24 \pm 2.23$ & $64.63 \pm 3.52$ & $65.50 \pm 2.15$ & $67.45 \pm 2.20$ & $62.00 \pm 2.25$ \\
WG & $53.71 \pm 0.13$ & $53.99 \pm 0.23$ & $54.94 \pm 0.20$ & $56.88 \pm 0.13$ & $52.53 \pm 0.21$ \\
ADG & $1.24 \pm 0.12$ & $1.25 \pm 0.15$ & $1.26 \pm 0.05$ & $1.30 \pm 0.14$ & $1.23 \pm 0.03$ \\
SGR & $5.05 \pm 1.25$ & $5.18 \pm 1.26$ & $5.19 \pm 1.68$ & $5.25 \pm 1.23$ & $4.77 \pm 1.74$ \\
FCR & $1.04 \pm 0.02$ & $1.02 \pm 0.03$ & $1.05 \pm 0.04$ & $0.95 \pm 0.03$ & $1.07 \pm 0.02$ \\
SR & $67.25 \pm 1.47$ & $69.30 \pm 1.18$ & $68.00 \pm 1.92$ & $70.18 \pm 1.71$ & $66.50 \pm 1.32$
\end{tabular}

Different superscripts in the same row indicate significant difference $(P<0.05)$ among control and treatment groups; Ducan's multiple range test $\mathrm{P}=0.05$; The value expressed as a mean $\pm \mathrm{SD}$.

Table 3. The haematology of Rugose frogs fed with Arthrospira platensis supplemented diets for 8 weeks before and after challenging with Aeromonas hydrophila

\begin{tabular}{|c|c|c|c|c|c|}
\hline \multirow[t]{2}{*}{ Parameters } & \multicolumn{5}{|c|}{ Arthrospira platensis levels in diet (\%) } \\
\hline & $\mathrm{T} 1(0.0 \%)$ & $\mathrm{T} 2(1.5 \%)$ & T3 (3.0\%) & $\mathrm{T} 4$ (4.5\%) & T5 (6.0\%) \\
\hline \multicolumn{6}{|l|}{ Before-challenge test } \\
\hline 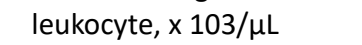 & $261.77 \pm 2.32^{\mathrm{b}}$ & $333.28 \pm 74.20^{\mathrm{a}}$ & $345.84 \pm 32.95^{a}$ & $362.96 \pm 1.02^{\mathrm{a}}$ & $289.82 \pm 35.04^{b}$ \\
\hline erythrocyte, $\times 10^{3} / \mu \mathrm{L}$ & $120.00 \pm 0.02^{\mathrm{b}}$ & $100.00 \pm 0.02^{\mathrm{b}}$ & $130.00 \pm 0.06^{b}$ & $190.00 \pm 0.10^{\mathrm{a}}$ & $120.00 \pm 0.06^{b}$ \\
\hline haemoglobin (HGB), g/dL & $7.56 \pm 0.015^{b}$ & $7.68 \pm 0.26^{b}$ & $7.73 \pm 1.63^{b}$ & $9.16 \pm 1.48^{\mathrm{a}}$ & $7.53 \pm 1.21^{\mathrm{b}}$ \\
\hline haematocrit $(\mathrm{HCT}), \%$ & $2.56 \pm 0.10^{c}$ & $2.96 \pm 0.42^{b}$ & $2.76 \pm 1.12^{\mathrm{b}}$ & $4.73 \pm 2.29^{a}$ & $2.40 \pm 0.49^{c}$ \\
\hline \multicolumn{6}{|l|}{ After-challenge test } \\
\hline leukocyte, $\times 10^{3} / \mu \mathrm{L}$ & $201.78 \pm 7.71^{b}$ & $217.71 \pm 7.79^{b}$ & $241.07 \pm 7.64^{\mathrm{a}}$ & $244.04 \pm 7.74^{\mathrm{a}}$ & $190.28 \pm 7.92^{c}$ \\
\hline erythrocyte, $\times 10^{3} / \mu \mathrm{L}$ & $210.00 \pm 0.43^{b}$ & $220.00 \pm 0.13^{a}$ & $210.00 \pm 0.04^{b}$ & $230.00 \pm 0.14^{\mathrm{a}}$ & $200.00 \pm 0.17^{c}$ \\
\hline haemoglobin (HGB), g/dL & $7.06 \pm 1.00$ & $6.73 \pm 0.50$ & $6.83 \pm 1.19$ & $7.16 \pm 0.40$ & $6.86 \pm 0.67$ \\
\hline haematocrit (HCT), \% & $4.93 \pm 1.59$ & $5.03 \pm 1.27$ & $5.20 \pm 0.46$ & $5.56 \pm 3.44$ & $5.26 \pm 1.50$ \\
\hline
\end{tabular}

Different superscripts in the same row indicate significant difference $(\mathrm{P}<0.05)$ among control and treatment groups; Ducan's multiple range test $\mathrm{P}=0.05$; The value expressed as a mean $\pm \mathrm{SD}$. 
4.5\% A. platensis dietary supplement exhibited higher values than other treatments, but there was no significant difference ( $P>0.05)$. However, levels of complement $C 3$ and IgG in frogs, fed with the $4.5 \% \mathrm{~A}$. platensis dietary supplement were the highest at $7.16 \pm 0.30 \mathrm{mg} / \mathrm{dL}$, and $308.67 \pm 1.15$ $\mathrm{mg} / \mathrm{dL}$, respectively, and there were significant differences $(P<0.05)$ when comparing with the control group.

\section{DISCUSSION}

In this study, Rugose frogs, fed with $4.5 \%$ A. platensis dietary, exhibited better growth relative to body weight, weight gain, average daily gain, specific growth rate, feed conversion ratio, and survival rate. This indicated that frogs on the Spirulina supplemented diets had normal metabolic response. Moreover, leukocyte, erythrocyte, haemoglobin, and haematocrit levels were significantly different compared with

Table 4. The level of phagocytic activity, reactive oxygen species (ROS), complement C3 and immunoglobulin G (IgG) of Rugose frogs fed with Arthrospira platensis supplemented diets for 8 weeks before and after challenging with Aeromonas hydrophila

\begin{tabular}{|c|c|c|c|c|c|}
\hline \multirow[t]{2}{*}{ Parameters } & \multicolumn{5}{|c|}{ Arthrospira platensis levels in diet (\%) } \\
\hline & $\mathrm{T} 1(0.0 \%)$ & $\mathrm{T} 2(1.5 \%)$ & T3 (3.0\%) & $\mathrm{T} 4(4.5 \%)$ & T5 (6.0\%) \\
\hline \multicolumn{6}{|l|}{ Before-challenge test } \\
\hline Phagocytic activity (30 minutes) & $1.87 \pm 1.42$ & $2.35 \pm 1.53$ & $2.36 \pm 1.44$ & $2.48 \pm 1.78$ & $2.33 \pm 0.71$ \\
\hline ROS (30 minutes) & $9.75 \pm 3.55$ & $9.83 \pm 5.82$ & $13.06 \pm 3.44$ & $14.11 \pm 5.41$ & $9.60 \pm 5.16$ \\
\hline Complement C3, mg/dL & $7.90 \pm 1.32$ & $8.13 \pm 1.18$ & $8.83 \pm 1.20$ & $8.86 \pm 1.34$ & $8.50 \pm 1.28$ \\
\hline $\operatorname{lgG}, \mathrm{mg} / \mathrm{dL}$ & $360.33 \pm 5.28$ & $366.33 \pm 5.20$ & $371.67 \pm 5.30$ & $381.33 \pm 5.38$ & $359.25 \pm 5.48$ \\
\hline \multicolumn{6}{|l|}{ After-challenge test } \\
\hline Phagocytic activity (30 minutes) & $21.86 \pm 2.81$ & $24.28 \pm 3.16$ & $22.35 \pm 1.18$ & $24.80 \pm 2.51$ & $21.28 \pm 2.95$ \\
\hline ROS (30 minutes) & $20.70 \pm 1.66$ & $20.35 \pm 1.68$ & $21.33 \pm 1.73$ & $23.98 \pm 1.84$ & $20.06 \pm 1.62$ \\
\hline Complement C3, mg/dL & $5.56 \pm 0.20^{\mathrm{b}}$ & $4.96 \pm 0.10^{c}$ & $4.66 \pm 0.13^{c}$ & $7.16 \pm 0.30^{\mathrm{a}}$ & $5.90 \pm 0.14^{b}$ \\
\hline IgG, mg/dL & $259.67 \pm 1.33^{b}$ & $267.00 \pm 1.30^{\mathrm{b}}$ & $301.33 \pm 1.20^{\mathrm{a}}$ & $308.67 \pm 1.15^{\mathrm{a}}$ & $274.67 \pm 1.22^{b}$ \\
\hline
\end{tabular}

Different superscripts in the same row indicate significant difference $(P<0.05)$ among control and treatment groups; Ducan's multiple range test $P=0.05$; The value expressed as a mean $\pm S D$.

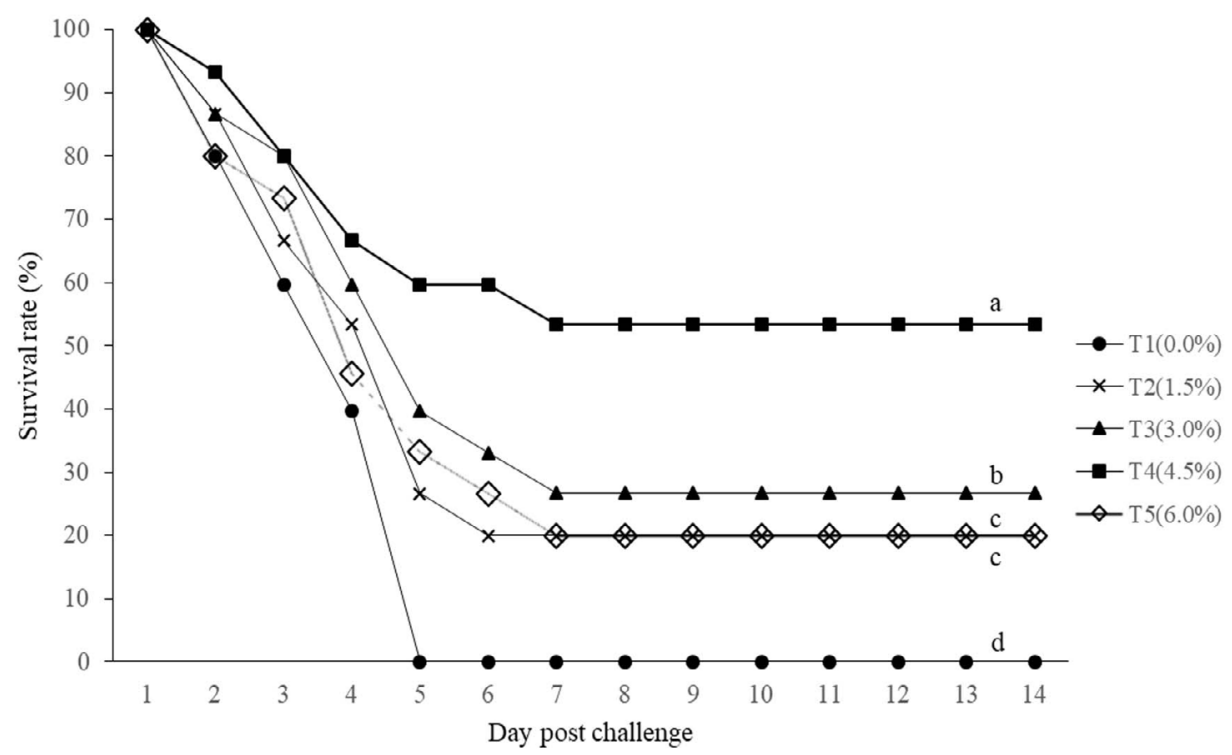

Fig. 1. Survival rate of Hoplobatrachus rugulosus fed different experimental diets containing different levels of Spirulina during two weeks challenge with Aeromonas hydrophila. 
the control treatment $(P<0.05)$. At the same time, a non-specific immune response including phagocytosis, ROS and complement $\mathrm{C} 3$ and a specific immune response such as IgG did not significantly differ from the control treatment $(P>0.05)$. On the other hand, using 6\% Spirulina dietary supplement may have decrease growth given its affect on the digestive system due to its being insectivore ${ }^{31}$. Similarly, Kiriratnikom et al ${ }^{32}$ reported that adding a $3 \% A$. platensis dietary supplement could stimulate the highest growth rate of Carassius auratus, but its growth rate declined when fed with a $5 \%$ A. platensis dietary supplement.

Furthermore, Liao et $\mathrm{al}^{33}$ found that the growth rate of Penaeus monodon, fed with a $5 \%$ Spirulina dietary supplement was lower than those fed without Spirulina. In other words, Arthrospira sp. is a potential protein content that provides crucial vitamins and mineral. However, using high concentrations of $A$. platensis in dietary supplements would be toxic and harmful to the survival rate and growth of aquatic animals ${ }^{18}$. Therefore, this suggests that adding $A$. platensis as a suitable dietary may impact differently on different aquatic animal species, and may influence feeding behaviour, and digestive system.

Moreover, this research indicate that combining $A$. platensis in dietary formulas can enhance the disease resistance of frogs against the infection of $A$. hydrophila. This conclusion is supported by the finding that after two weeks of challenge test with high disease concentration at $5.2 \times 10^{8} \mathrm{CFU} / \mathrm{mL}$, frogs, fed with $4.5 \%$ Spirulina dietary supplement, had the highest survival rates at $53.33 \%$ which was higher in comparison with the other treatments . In contrast, $100 \%$ mortality occurred in the control group within five days.

The results indicated that frogs receiving Spirulina dietary supplements were able to resist A. hydrophila, and exhibited significantly greater haematology and non-specific and specific immune responses than control treatment $(P<0.05)$. This scenario indicated that Spirulina contains a necessary stimulant that encourages immunological responses such as phycocyanin, carotenoids, and fatty acids, particularly GLA ${ }^{18,21}$. Using a $4.5 \%$ Spirulina dietary supplement appeared to significantly increase levels of leukocyte and erythrocyte $(P<0.05)$ compared with control treatment. The increased levels of leukocyte and erythrocyte indicated an excellent immune response because the function of leukocyte cells is to destroy foreign matters passing into the body. Moreover, erythrocyte appeared to facilitate the distribution of oxygen to individual body parts, leading to a healthy body. Correspondingly, Khalil et $\mathrm{al}^{11}$ studied the effects of using Spirulina in dietary supplements on disease resistance and immune response in Cyprinus carpio L. The results revealed that Spirulina can boost an amount of fish's erythrocyte and leukocyte. Likewise, Adel et al $^{9}$ studied the effects of adding Spirulina as a dietary supplement on growth and immune responses and disease resistance in the great sturgeon (Huso huso) and reported that using a $10 \%$ Spirulina dietary could significantly enhance the growth and immune response, and disease resistance than those in the control treatment $(\mathrm{P}<0.05)$

Additionally, Cao et al $^{12}$ studied the effects of using Spirulina instead of fish meal as a dietary supplement on growth, immune response, and disease resistance in relation on $A$. hydrophila infections in gibel carp (Carassius auratus gibelio var. CAS III) This research indicated that a dried spirulina dietary supplement was effective in enhancing growth and improving immune response. Chen et $\mathrm{al}^{10}$ investigation involved using Spirulina to stimulate a non-specific immune response and disease resistance to the Vibrio alginolyticus in Litopenaeus vannamei. Their findings indicated that Spirulina, in the form of a dried powder (SDP) at a ratio of 30 grams per 1 kilogram dietary can significantly stimulate a non-specific immune response due to an increased lysozyme activity, and a better phagocytic activity than those in the control treatment $(P<0.05)$. Moreover, SDP can master the capability in disease resistance of the infection of Vibrio alginolyticus, so their survival rate and growth of L. vannamei are significantly $(P<0.05)$ higher than the control treatment (without SDP)

Complement is a protein in serum that responds, as non-specific immune response to foreign matter in an organism is an indicator of disease resistance. Complement activity, measured from complement $\mathrm{C} 3$, is the exudated substance to get rid of foreign matters passing through the body, and it demonstrates one of the 
non-specific immune responses. The function of complement C3 from frogs' body to aid leukocyte or to be opsonin substance for opsonization process, which uses opsonins to tag foreign pathogens for elimination by phagocytes ${ }^{34}$. In this research, results showed that Rugose frogs, fed with a $4.5 \%$ Spirulina dietary supplement, had the highest complement C3 with a significant difference $(P<0.05)$ compared with control treatment, those frogs did not received Spirulina dietary supplement, and more particularly those frogs after injection with $A$ hydrophila.

Likewise, Sheikhzadeh et a $\mathrm{I}^{15}$ conducted similar studies using Spirulina to ascertain immune response in rainbow trout (Oncorhynchus mykiss) by measuring exudated substances. Results found that using a $2.5 \%$ Spirulina dietary supplement lead to a higher levels of lysozyme, complement C3, and immunoglobulin M (IgM) in contrast to control treatments with a significant difference $(P<0.05)$. Moreover, it assembles many leukocyte cells at the site where the foreign matters emerged. Consequently, this causes inflammation, and after that, phagocyte cells can destroyed foreign matters by making disease cell lysis while the organism's cells are not destroyed or may die like apoptosis, not necrosis. Therefore, a $4.5 \%$ Spirulina dietary supplement has the potential to enhance the immune response in Rugose frogs by increasing the amount of complement $\mathrm{C} 3$ in the blood to eliminate infection from frogs' bodies when comparing with control group. Also, exudated substances such as antibody or immunoglobulin can indicate specific immune responses, and this research found that Rugose frogs, fed with a $4.5 \%$ Spirulina dietary could produce the higher IgG with significant difference $(P<0.05)$ compared with control group in particular after injecting disease to frogs. Interestingly, there have not been any studies concerning using Spirulina to stimulate the specific immune response in Rugose frog. The mechanism of specific immune response will help eradicate the foreign matters passing into an organism by producing antibody or immunoglobulin as protein compound substances that are exudated from plasma cells that are transformed B lymphocyte. Given the ability to have an immune response an organism can get rid of a disease or foreign matters and recognize those diseases that will rapidly destroy it if the same infection occurs in the organism ${ }^{34}$.

\section{CONCLUSIONS}

This study indicated that Spirulina (Arthrospira platensis) can be effectively used as functional feed additive to enhance growth, haematological parameters, immune responses, and $A$. hydrophila resistance in the cultivation of Rugose frogs using cement tanks in cultivation system. Spirulina at 45 grams per 1 kilogram of diet (4.5\%) is a suitable level to boost non-specific immune response (phagocytic activity, ROS, and complement C3) and specific immune response $(\operatorname{IgG})$ in Rugose frogs.

\section{ACKNOWLEDGMENTS}

We would like to thank the Department of Fisheries, Faculty of Agriculture, Faculty of Associated Medical Sciences, Khon Kaen University for facilitating laboratory throughout the study.

\section{CONFLICT OF INTEREST}

The authors declare that there is no conflict of interest.

\section{AUTHORS' CONTRIBUTION}

All authors listed have made a substantial, direct and intellectual contribution to the work, and approved it for publication.

\section{FUNDING}

This work was supported by the Sakon Nakhon Rajabhat University, Thailand for providing financial support through Grant Number : 0208/2557.

\section{DATA AVAILABILITY}

All datasets generated or analyzed during this study are included in the manuscript.

\section{ETHIC STATEMENTS}

This study protocols were approved by the Institutional Animal Care and Use Committee of Khon Kaen University, based on the Ethic of Animal Experimentation of National Council Research of Thailand (Record No. IACUC-KKU-101/61, Reference No. 0201.2.11/93). 


\section{REFERENCES}

1. Glorioso JC, Amborski RL, Amborski GF, Culley DD. Microbiological studies on septicemic bullfrogs (Rana catesbeiana). Am J Vet Res. 1974;35(9):1241-1245.

2. Hird DJ, Diesch SL, McKinnell RG, et al. Aeromonas hydrophila in wild-caught frogs and tadpoles (Rana pipiens) in Minnesota. Lab Anim Sci. 1981;31(2):166169.

3. Nyman S. Mass mortality in larval Rana sylvatica attributable to the bacterium, Aeromonas hydrophila. J Herpetol. 1986;20(2):196-201. doi: 10.2307/1563944

4. Chinabut $S$, Areekij S. Comparative study on the integumentary system of tadpole and adult frog (Rana tigerina). Proceeding of the Department of Fisheries of Thailand Annual Seminar;1995. Bangkok, Thailand. https://assets.publishing.service. gov.uk/media/57a08db2ed915d622c001b27/ RLAquatechreportR6206Cb.pdf

5. Taylor SK, Green DE, Wright KM, Whitaker BR. Bacterial Diseases. In: Wright KM, Whitaker BR, Editors. Amphibian Medicine and Captive Husbandry, Original ed. Florida: Krieger Publishing Company. 2001:159179.

6. Abdel-Tawwab M, Ahmad MH. Live Spirulina (Arthrospira platensis) as a growth and immunity promoter for Nile tilapia, Oreochromis niloticus (L.), challenged with pathogenic Aeromonas hydrophila. Aquac Res. 2009;40(9):1037-1046. doi: 10.1111/j.1365-2109.2009.02195.x

7. Ibrahem MD, Mohamed MF, Ibrahim MA. The role of Spirulina platensis (Arthrospira platensis) in growth and immunity of Nile tilapia (Oreochromis niloticus) and its resistance to bacterial infection. J Agric Sci. 2013;5(6):109-117. doi: 10.5539/jas.v5n6p109

8. Teimouri M, Amirkolaie AK, Yeganeh S. The effects of Spirulina platensis meal as a feed supplement on growth performance and pigmentation of rainbow trout (Oncorhynchus mykiss). Aquaculture. 2013;369399:14-19. doi: 10.1016/j.aquaculture.2013.02.009

9. Adel M, Yeganeh S, Dadar M, Sakai M, Dawood MAO. Effects of dietary Spirulina platensis on growth performance, humoral and mucosal immune responses and disease resistance in juvenile great sturgeon (Huso huso Linnaeus, 1754). Fish Shellfish Immunol. 2016;56:436-444. doi: 10.1016/j.fsi.2016.08.003

10. Chen YY, Chen JC, Tayag CM, et al. Spirulina elicits the activation of innate immunity and increases resistance against Vibrio alginolyticus in shrimp. Fish Shellfish Immunol. 2016;55:690-698. doi: 10.1016/j. fsi.2016.06.042

11. Khalil SR, Reda RM, Awad A. Efficacy of Spirulina platensis diet supplements on disease resistance and immune-related gene expression in Cyprinus carpio L. exposed to herbicide atrazine. Fish Shellfish Immunol. 2017;67:119-128. doi: 10.1016/j.fsi.2017.05.065

12. Cao S, Zhang P, Zou T, et al. Replacement of fishmeal by Spirulina Arthrospira platensis affects growth, immune related-gene expression in gibel carp (Carassius auratus gibelio var. CAS III), and its challenge against Aeromonas hydrophila infection. Fish Shellfish Immunol. 2018;79:265-273. doi: 10.1016/j. fsi.2018.05.022
13. Mahmoud MMA, El-Lamie MMM, Kilany OE, Dessouki AA. Spirulina (Arthrospira platensis) supplementation improves growth performance, feed utilization, immune response, and relieves oxidative stress in Nile tilapia (Oreochromis niloticus) challenged with Pseudomonas fluorescens. Fish Shellfish Immunol. 2018;72:291-300. doi: 10.1016/j.fsi.2017.11.006

14. Raji AA, Alaba PA, Yusuf H, et al. Fishmeal replacement with Spirulina platensis and Chlorella vulgaris in African catfish (Clarias gariepinus) diet: Effect on antioxidant enzyme activities and haematological parameters. Res Vet Sci. 2018:119:67-75. doi: 10.1016/j.rvsc.2018.05.013

15. Sheikhzadeh N, Mousavi S, Hamidian G, Firouzamandi M, Oushani AK, Mardani K. Role of dietary Spirulina platensis in improving mucosal immune responses and disease resistance of rainbow trout (Oncorhynchus mykiss). Aquaculture. 2019;510:1-8. doi: 10.1016/j. aquaculture.2019.05.009

16. Phang SM, Chu WL. Catalogue of Strains, University of Malaya Algae Culture Collection (UMACC). Institute of Postgraduate Studies and Research. Kuala Lumpur: University of Malaya. 1999.

17. Soheili M, Khosravi-Darani K. The potential health benefits of algae and micro algae in medicine: a review on Spirulina platensis. Curr Nutr food Sci. 2011;7(4):279285. doi: $10.2174 / 157340111804586457$

18. Gutierrez-Salmean G, Fabila-Castillo L, ChamorroCevallos $\mathrm{G}$. Nutritional and toxicological aspects of Spirulina (Arthrospira). Nutr Hosp. 2015;32(1):34-40.

19. Mathur M. Bioactive Molecules of Spirulina: A Food Supplement. In: Merillon JM, Ramawat K, Editors. Bioactive Molecules in Food. Reference Series in Phytochemistry. Cham: Springer Nature Switzerland AG. 2019:1621-1642. doi: 10.1007/978-3-319-780306_97

20. Menegotto AL, Souza LE, Colla LM, et al. Investigation of techno-functional and physicochemical properties of Spirulina platensis protein concentrate for food enrichment. LWT-Diet Sci Technol. 2019;114:108267. doi: 10.1016/j.lwt.2019.108267

21. Brito AdF, Silva AS, de Oliveira CVC, et al. Spirulina platensis prevents oxidative stress and inflammation promoted by strength training in rats: dose-response relation study. Sci Rep. 2020;10:6382. doi: 10.1038/ s41598-020-63272-5

22. Mansano CF, Vanzela LS, Americo-Pinheiro JH, et al. Importance of Optimum Water Quality Indices in Successful Frog Culture Practices. In: Gokce D, editor. Limnology: Some New Aspects of Inland Water Ecology. London: Intech Open Ltd. 2018:133-154.

23. APHA, AWWA, WEF (American Public Health Association, American Water Works Association, and Water Environment Federation). Standard Methods for examination of water and wastewater. $22^{\text {nd }}$ ed. Washington, DC: American Public Health Association. 2012.

24. Somsueb P, Boonyaratpalin M. Optimum protein and energy levels for the Thai native frog, Rana rugulosa Weigmann. Aquac Res. 2001;32(1):33-38. doi: 10.1046/j.1355-557x.2001.00033.x

25. AOAC (Association of Official Analytical Chemists). 
Official Methods of Analysis, $15^{\text {th }}$ ed. Washington, DC: The Association of Official Analytical Chemists. 1990.

26. NRC (National Research Council). Nutrition Requirement of Fish. Washington, DC: National Academy Press; 1993.

27. Smith JM, Stump KC. Isoflurane anesthesia in the African clawed frog (Xenopus laevis). Contemp Top Lab Anim Sci. 2000;39(6):39-42.

28. Heatley JJ, Johnson M. Clinical technique: Amphibian hematology: A practitioner's guide. J Exotic Pet Med. 2009;18(1):14-19. doi: 10.1053/j.jepm.2008.10.004

29. Adan A, Alizada G, Kiraz Y, Baran Y, Nalbant A. Flow cytometry: basic principles and applications. Crit Rev Biotechnol. 2017;37(2):163-176. doi: 10.3109/07388551.2015.1128876

30. Shehan C. Clincal immunology principal and laboratory diagnosis $2^{\text {nd }}$ Ed. Lipocortt -Raven Publishers, Philadelphia. 1997.
31. Boonta T, Chitmanut C, Promya J. Effects of Spirulina platensis, Cladophora sp. and Allium sativum supplementary diets on growth performance, reproductive maturity, and phagocytic activity in common lowland frog (Rana rugulosa). J Fish Tech Res. 2012;6(1):23-35.

32. Kiriratnikom S, Zaau R, Suwanpugdee A. Effects of various levels of Spirulina on growth performance and pigmentation in goldfish (Carassius auratus). Songklanakarin J Sci Technol. 2005;27(Suppl. 1):133139.

33. Liao WL, Nur-E-Borhan SA, Okada S, Matsui T, Yamaguchi K. Pigmentation of culture black tiger prawn by feeding with a Spirulina-supplemented diet. Nippon Suisan Gakk. 1993;59(1):165-169. doi: 10.2331/suisan.59.165

34. Williamson H.Amphibian Immunology. Department of Microbiology, Tennessee University. 2014. 